\title{
PEMANFAATAN TONG BEKAS SEBAGAI KARYA DESAIN INTERIOR
}

\author{
Noprita Elisabeth Sianturi \\ Fakultas Seni dan Desain \\ Universitas Potensi Utama
}

Jl. K.L. Yos Sudarso Km 6,5 No. 3A Tanjung Mulia Medan Sumatera Utara 20241 Indonesia

noprita_elisabeth@potensi-utama.ac.id

\begin{abstract}
ABSTRAK
Karya Desain Interior adalah sebuah karya yang dihasilkan atau dibuat dapat dipajang atau diletakkan ke dalam sebuah ruangan atau rumah dan dapat juga diletakkan diluar rumah/lingkungan tergantung karya yang dihasilkan, karya tersebut dibuat untuk mempercantik ruangan atau rumah atau memperindah luar ruangan, ada beberapa macam karya yang dibuat untuk memperindah ruangan atau rumah serta lingkungan antara lain karya yang dihasilkan dari tong. Hasil karya yang dibuat dari tong ini adalah tempat duduk, tong yang digunakan dalam membuat karya desain interior ini adalah tong bekas, dengan membuat tempat duduk dan meja dengan menggunakan tong bekas atau sisa bahan industri ini tentunya memanfaatkan bahan yang sudah tidak dipergunakan lagi untuk menghasilkan sebuah karya yang bisa dimanfaatkan untuk kehidupan sehari-hari. Dalam pembuatan tempat duduk dan meja ini tidak hanya menggunakan tong saja tentunya juga menggunakan triplek sebagai pelengkap tempat duduk tempat duduk tersebut. Pemilihan tong bekas dan triplek ini dengan dasar bahan mudah didapat dan harganya ekonomis dan ada kesan minimalis dan ringan.
\end{abstract}

Kata Kunci : tempat duduk, tong bekas, triplek, karya desain interior

\begin{abstract}
Interior Design Work is a work that is produced or made can be displayed or placed into a room or house and can also be placed outside the house / environment depending on the work produced, the work is made to beautify the room or house or beautify the outdoors, there are several kinds of works made to beautify the room or house and the environment, among others, works produced from barrels. The work made from this barrel is a seat, the barrel used in making this interior design work is a used barrel, by making a seat and table using used barrels or the rest of the industrial material of course utilizing materials that are no longer used to produce a works that can be used for everyday life. In making a seat and table not only using a barrel, it also uses plywood as a complement to the seating seat. This selection of used and plywood barrels with basic ingredients is easily available and the price is economical and there is a minimalist and light impression.
\end{abstract}

Keywords : seating, used barrels, plywood, interior design works

\section{PENDAHULUAN}

Perkembangan karya dimasa sekarang sangat maju mengunakan bahan dasar tong atau kaleng cat untuk membuat meja 1 set ( 4 kursi \& 1 meja ). Dengan bahan ini dapat mengahsilkan laba baru di dunia industri bahkan sangat menjanjikan karna produk ini dapat dijual belikan dengan harga yang cukup mecengangkan. Waktu pemakaian cukup baik bisa 
dingunakan dengan jangka waktu panjang. Tidak hanya untuk memperindah dekorasi interior suatu ruangan saja tapi benda ini memiliki fungsi. Dengan berkesan sederhana tapi unik. Banyak sekarang digunakan di cafe tempat anak anak muda ngumpul. Pengelohan dengan prinsip reduce, reuse, recycle dan DIY (Do It Yourself) dapat mengurangi jumlah tumpukan barang.

Tujuannya dalam pembuatan ini adalah untuk memaksimalkan bahan bekas dari limbah industri yang dapat dimanfaatkan menjadi sebuah karya desain interior yang dapat digunakan didalam ruangan atau rumah dengan biaya yang sangat ekonomis dan tampilannya pun minimalis.

\section{STUDI LITERATUR}

Berdasarkan informasi dan data yang sudah didapat, maka proses dan tahapan dalam merancang atau membuat karya desain interior ini mudah dicerna dan baik sekaligus sistematis maka dapat beberapa langkah yaitu penyusunan metode, strategi, perancangan yang terstruktur.

\section{A. Metode Perancangan}

Untuk mendapatkan hasil yang maksimal dari perancangan karya desain interior ini yang baik dan efektif, dan tujuan yang diinginkan tercapai, maka ada beberapa cara atau metode yang harus dilakukan.

\section{B. Ruang Lingkup Perancangan}

Agar dalam pembuatan furniture atau meja dan kursi ini lebih khusus sehingga maksud yang diinginkan tercapai, maka dibuatlah ruang lingkup dalam pembuatan karya desain interior ini dari bahan tong bekas dan triplek. Target yang ingin dicapai dalam pembuatan karya ini adalah semua orang atau masyarakat luas dengan target sebagai berikut :

\section{Demografis}

Usia : remaja, orang tua

Jenis kelamin : laki-laki dan perempuan

\section{Geografis}

Lokasi untuk pemasangan desain ini adalah seluruh kota Medan.

\section{Pisikografi}

Targetnya adalah karya desain interior ini dapat dipasang di berbagai tempat dan kalangan masyarakat luas.

\section{Metode Pengumpulan Data \\ 1. Data verbal}

a) Wawancara

wawancara dilakukan dengan menghubungi beberapa nara sumber untuk bertanya tentang karya desain interior, dalam wawancara tersebut harus melalui dengan bertahap agar data yang diperoleh lebih lengkap dan akurat, data yang ditanyakan tentang Karya Desain Interior, segi ergonomis, dan ekonimis,

b) Observasi 
Observasi dilakukan untuk melihat secara langsung ke sebuah tempat pembuatan furniture beberapa karya desain interior yang telah dibuat dari beberapa barang bekas industri yang laing atau karya dengan model atau bentuk yang berbeda tetapi menggunakan bahan dari tong bekas juga.

\section{Landasan Teori}

\section{Tong bekas}

Tong bekas adalah sebuah drum yang berbentuk silinder dan ukurannya ada yang besar dan kecil terbuat dari bahan seng yang agak tebal, tong yang digunakan untuk pembuatan kursi dan meja ini berasal dari bahan industri yang sudah tidak digunakan lagi dan aman untuk pembuatan furniture tersebut.

\section{Desain Interior}

Menurut lazimnya, makna dari desain interior adalah sebuah desain yang dibuat untuk diletakkan di dalam ruangan atau rumah. Desain interior bisa juga diartikan sebagai menata sebuah karya atau perabot atau alat rumah tangga yang disusun sedemikian rupa dengan tampilan yang menarik. Dalam membuat desain interior ada beberapa aspek yang harus diketahui untuk merancang bagian ruangan atau rumah antara lain dimulai perencanaan desain, riset, koordinasi dan sebagainya.

Desain interior dapat merupakan gabungan dari beberapa unsur seperti seni dan ilmu sains agar menghasilkan sebuah karya desain interior yang menarik sekaligus indah serta mempunyai manfaat. Namun demikian, seorang yang mampu membuat desain interior yang baik mampu menghitung segala ukuran ruangan atau rumah dengan tepat, unsur-unsur yang dibutuhkan untuk desain dan sebagainya. Fungsi dari desain interior dapat membuat ruangan atau rumah jadi kelihatan menarik, cantik dan baik. Ruangan atau rumah yang didesain dapat diisi dengan berbagai perabotan atau interior yang baik dan maksimal sesuai dengan keguaan ruangan tersebut.

Desain interior adalah sebuah ilmu yang mempelajari tentang merancang sebuah karya atau desain untuk dibuat dalam sebuah ruangan atau rumah dan dapat difungsikan membantu manusia dalam mendesain letak sebuah karya. Dan bidang keilmuan tersebut berdasarkan pada desain, bidang keilmuan ini mempunyai tujuan untuk menciptakan sebuah ruangan atau rumah yang menarik disertai dengan bantuan elemen-elemen yang lain, baik itu secara fisik ataupun nonfisik. Merancang interior diantaranya adalah mengenai arsitektur yang terdapat bagian dalam suatu bangunan. Misalnya: merancang desain interior ruangan yang menarik dan efisien.

Tentunya kita dapat melihat dan masuk ke dalam bagian rumah dimana dari luar terlihat seperti sempit, tetapi pada saat masuk ke dalam rumah tersebut mempunyai kesan jauh lebih luas. Atau demikian juga kebalikannya, ada rumah yang terlihat cukup luas namun apabila dilihat bagian dalam rumah terlihat seperti sempit dikarenakan ruangan tersebut tidak ditata dengan rapi..

Maka dari itu, untuk menata rumah tersebut sangat memerlukan ilmu desain interior untuk membantu merancang desain isi dari rumah tersebut. Dengan bantuan desain interior 
maka akan kita akan dapat merancang sebuah desain dengan maksimal untuk setiap segi yang ada dirumah dan sekaligus dapat memaksimalkan penataan setiap sudut ruangan. Seperti posisi dapur, kamar tidur, kamar mandi dan sebagainya.

Ada sebagian rumah yang sudah di set sedemikain rupa oleh penjual. Namun, dengan peran desain interior tentunya dapat mendesain ruangan tersebut sesuai dengan selera masing-masing serta kita dapat meminta pendapat seseorang yang ahli dala mendesain ruangan tersebut untuk menentukan posisi yang cocok setiap ruangan.

Mengenai desain interior kita harus juga memperhatikan beberapa hal yang lain salah satunya adalah segi estetika. Tentunya seperti yang diketahui bahwa desain interior adalah penggabungan antara sains dan seni. Dengan kata lain, kita lah yang menentukan ruamah tersebut mau ditempati sendiri atau akan disewakan kepada orang lain.

Desain interior rumah tidak segampang yang diperkirakan dikarenakan rumah tersebut adalah sebuah tempat yang akan ditempati bersama dan tempat untuk kumpul bersama dengan keluarga yang lain. Maka dari itu rumah tersebut harus ditata dengan maksimal dan penempatan dari perabotan atau furnitur nya harus disesuaikan agar rumah tersebut kelihatan menarik..

\section{HASIL DAN PEMBAHASAN}

1.1. Pembahasan

1.2. Strategi Perancangan

Memilih Tempat Duduk sebagai Tema :

- Melihat dari aspek fungsional, keindahan, dan kenyamanan.

1. Dari segi aspek Fugsioanl : mengolah bahan bekas drum atau tong dari yang tidak memiliki nilai menjadi bernilai tinggi.

2. Dari segi aspek keindahan : bentuk yang unik, menarik dan sederhana memiliki kesan minimalis.

3. Dari segi aspek kenyamanan : ukuran yang menjadi pertimbangan utama yang menjadi kelayakan ruang gerak pengguna.

- Merancang kursi dan meja dari bahan dasar tong atau drum melihat nilai ergonomis dan kelayakan standar dimensi gerak agar lebih enak digunakan untuk kursi dan meja.

Ukuran :

- Drum untuk Kursi

1. Tinggi :35-43 Cm

2. Untuk Dudukan $\quad: 50-71 \mathrm{Cm}$

- Kayu untuk Lapisan

1. Kayu dengan tebal : $2 \mathrm{~cm}$ dan lebar $10 \mathrm{~cm}$

2. Panjang kayu antara : $100 \mathrm{~cm}$ sampai $120 \mathrm{~cm}$.

\section{Media Planning}


Alat-alat dan bahan-bahan yang di gunakan :

1. Gambaran Pola

2. Tong bekas minyak/oli

3. Kayu

4. Cat Mobil yaitu : Penta Gloss

5. Lem Kayu, Lem G, Paku, Baut

- Alat

1. Pertukangan Listrik : gerinda, bor, pasah atau planner

2. Pertukangan Manual : obeng, palu pisau, ragum, catut, parang, gergaji, pasah manual.

3. Alat Las (Welding) : Alat Las Listrik, Alat Las Actylin

4. Peralatan Finishing : kompresor dan spray gun

Cara membuatnya :

1. Menyiapkan tong yang akan dipakai.

2. Kemudian tong tersebut dibersihkan dengan secara teliti baik itu meliputi bagian luar dan dalam.

3. Setelah kelihatan bersih, tong dijemur agar kelihatan mengering. Lalu potong drum sesuai dengan keinginan dengan mesin gerinda, sesuai bentuk kursi, meja yang akan dibuat.

4. Setelah selesai dipotong tong harus didempul, lalu epoxy tidak dapat langsung ditumpangi dengan cat, tong harus dihaluskan semua permukaannya dengan cara diamplas setelah kelihatan tongnya sudah halus lakukan pengecatan keseluruhan daripada tong bekas.

5. Setelah tong selesai dicat, tong tersebut dijemu dibawah sinar matahari sampai cat pada tong tersebut kelihatan kering.

6. Setelah cat pada tong mengering, kemudian kayu yang sudah dipotong diletakkan pada tempat yang telah ditentukan.

7. Untuk mengencangkan kayu dan besi dapat dilakukan menggunakan baut dan dapat juga menggunakan sifat elastis dari plat besi.

8. Setelah dilakukan finishing pada kayu menggunakan sealer sanding dimana gunanya untuk mematikan serat kayu sehingga dapat memudahkan dalam proses pengamplasan, lalu ditutup dengan menggunakan vernis transparan agar warna alami kayu tetap terjaga.

9. Kursi atau meja dari bahan tong bekas yang sudah selesai dikerjakan dapat diletakkan pada berbagai ruangan rumah.

Nilai Estetika dari kursi dan meja yang dibuat:

1. Bentuknya yang sederhana memiliki kesan minimalis dan ringan.

2. Warna yang digunakan pada kursi yaitu hitam memberi kesan yang kuat dan berat, selain itu efek dari warna yang digunakan juga dapat mendukung bentuk kursi terlihat lebih minimalis.

3. Warna kayu tidak berubah agar kayu terlihat lebih alami.

4. Bentuk meja yang bulat memberikan kesan sederhana dan menarik.

\section{Visualisasi Sketsa}




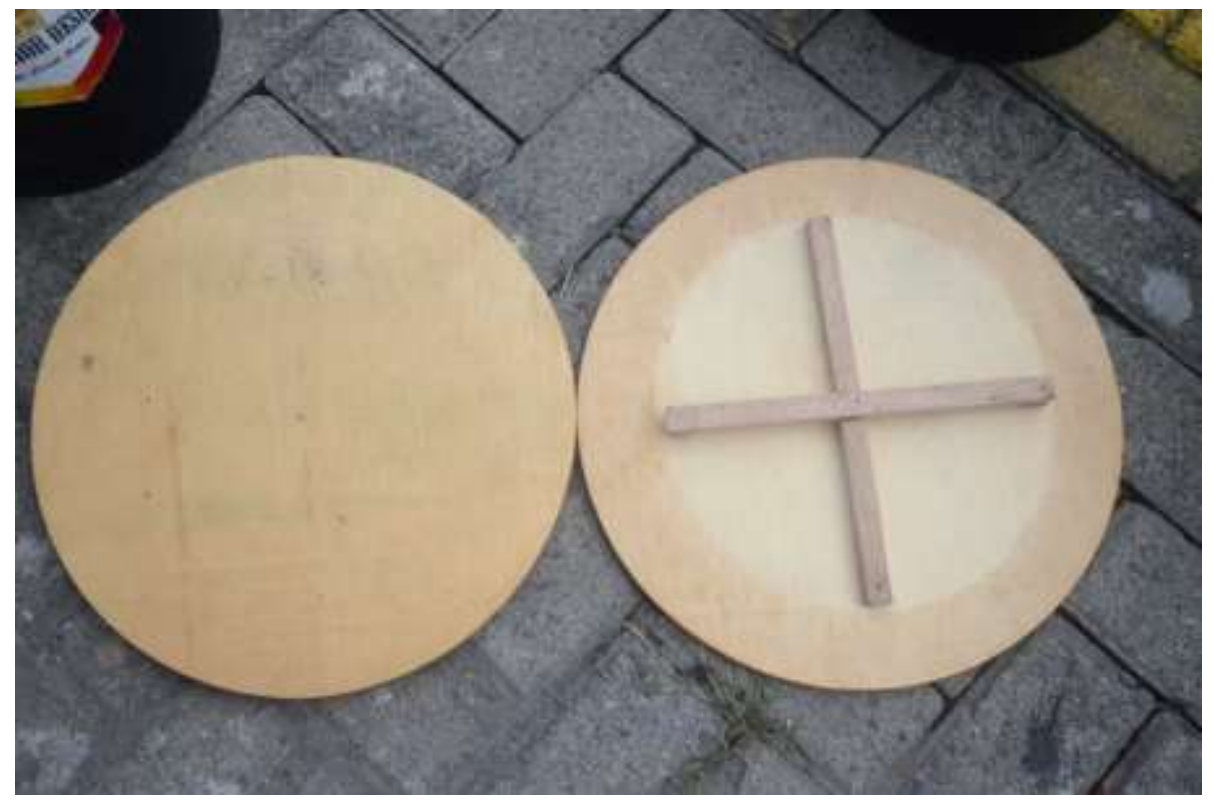

Gambar 1. Sketsa alas tempat duduk

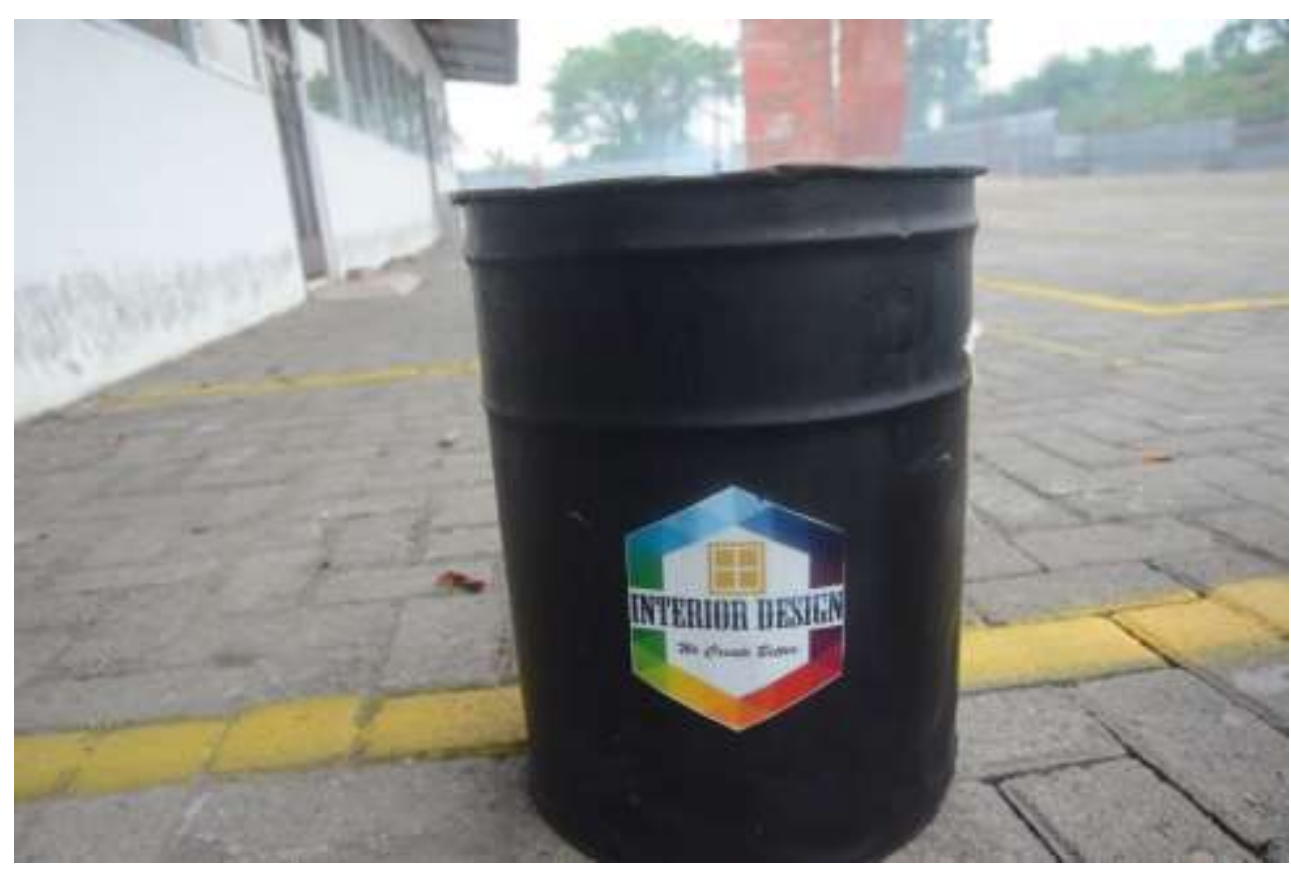

Gambar 2. Tong yang digunakan untuk tempat duduk dan meja 


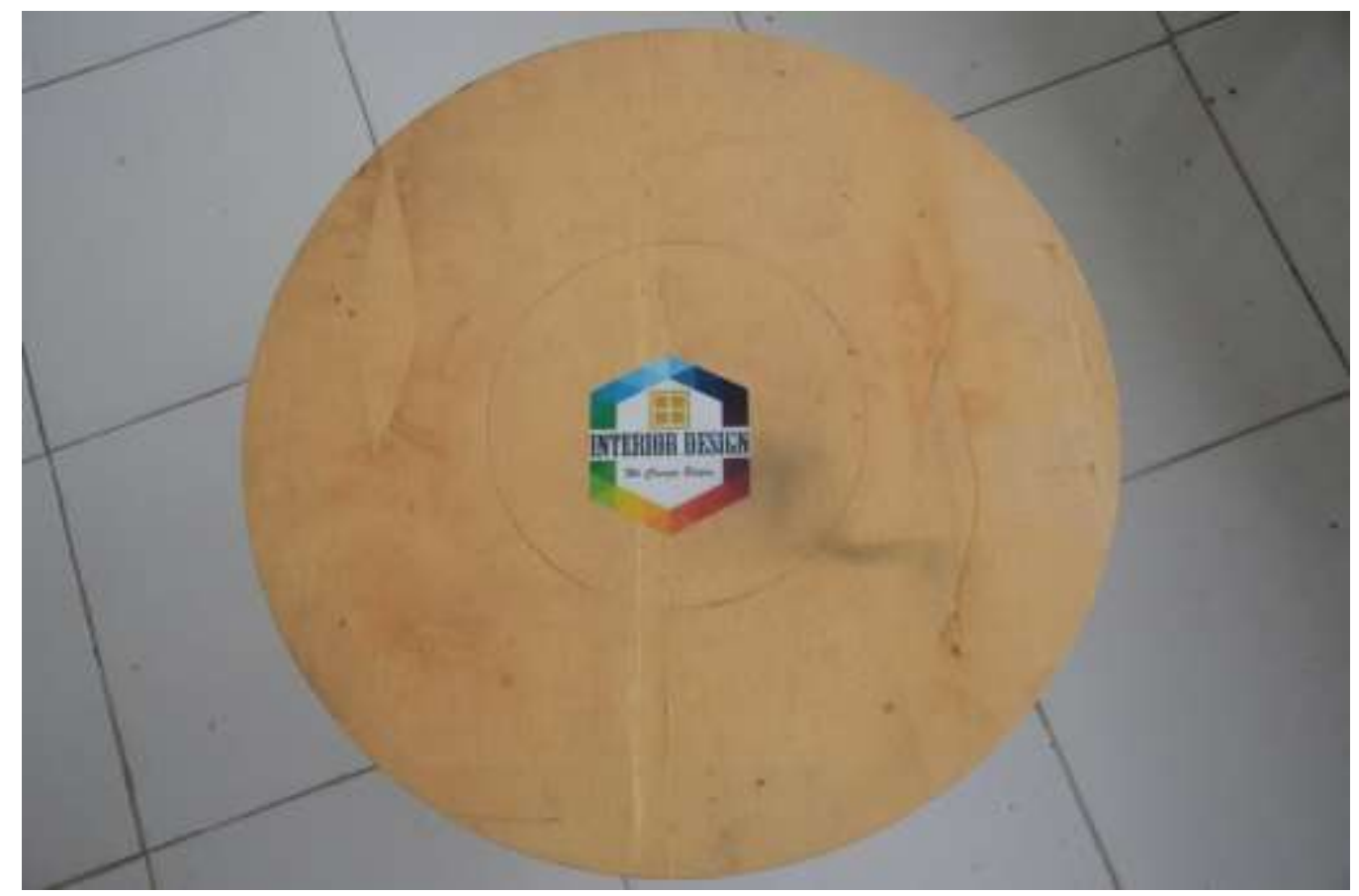

Gambar 3. Desain untuk meja

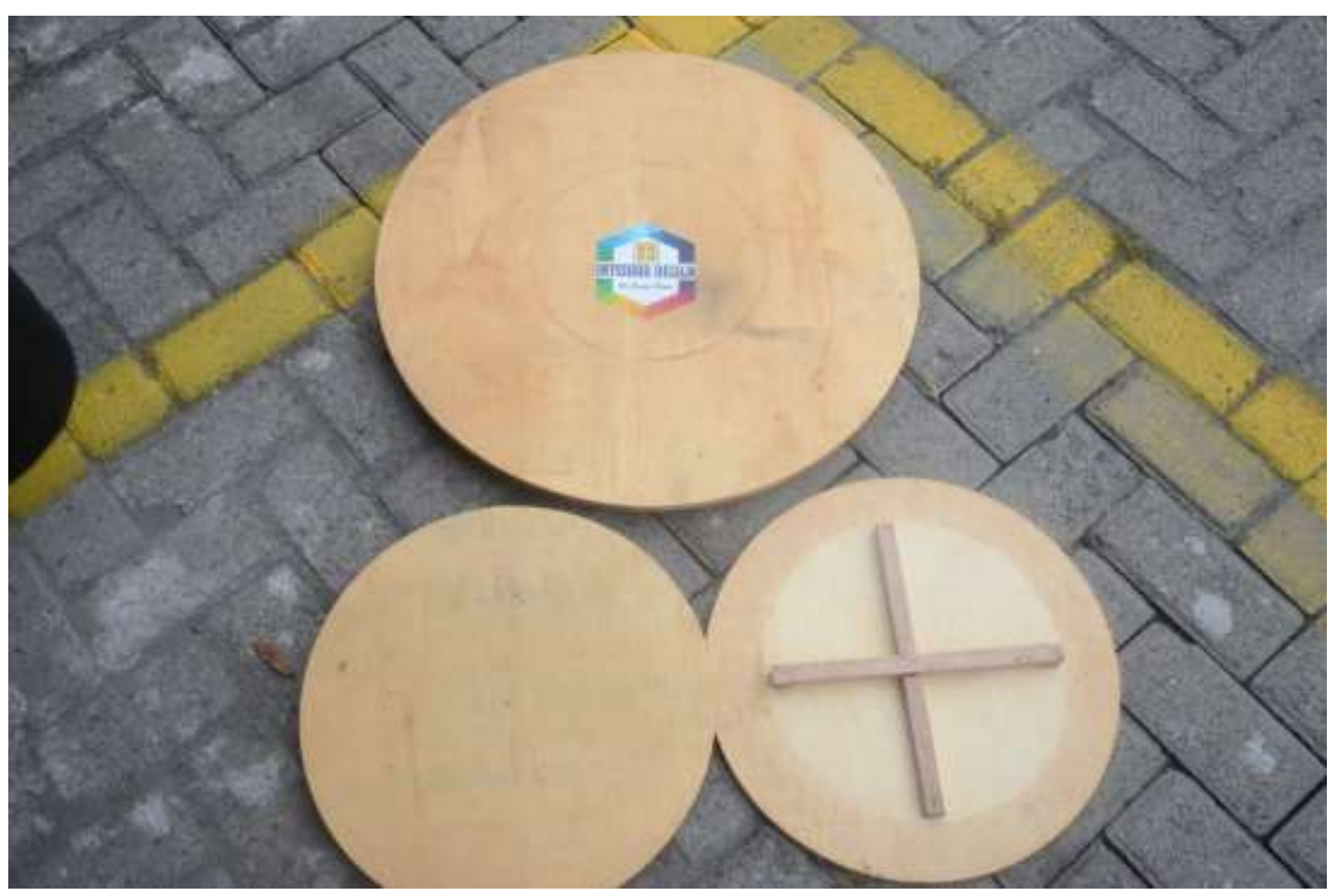

Gambar 4. Desain alas untuk meja dan tempat duduk 


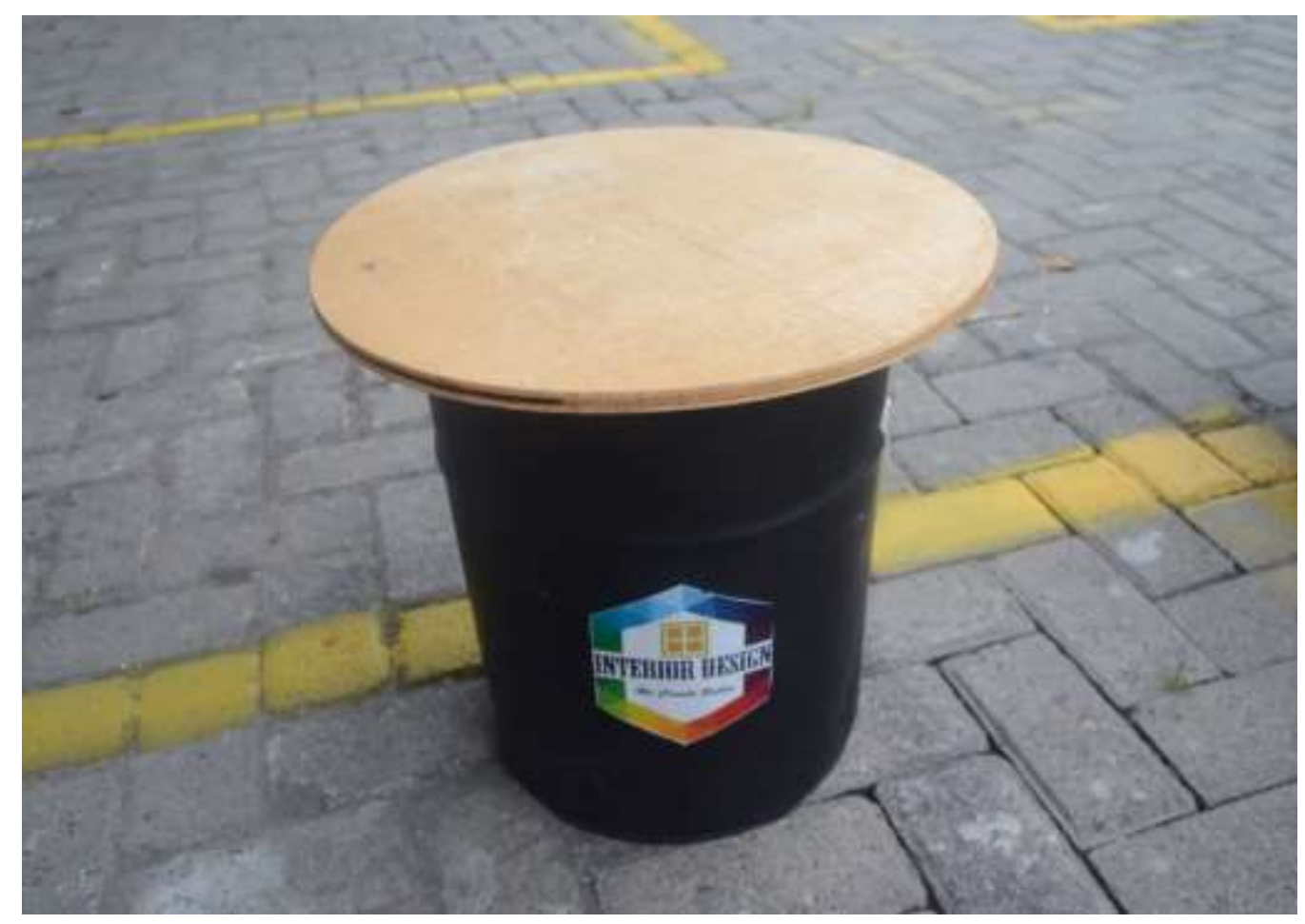

Gambar 5. Desain tempat duduk yang sudah jadi

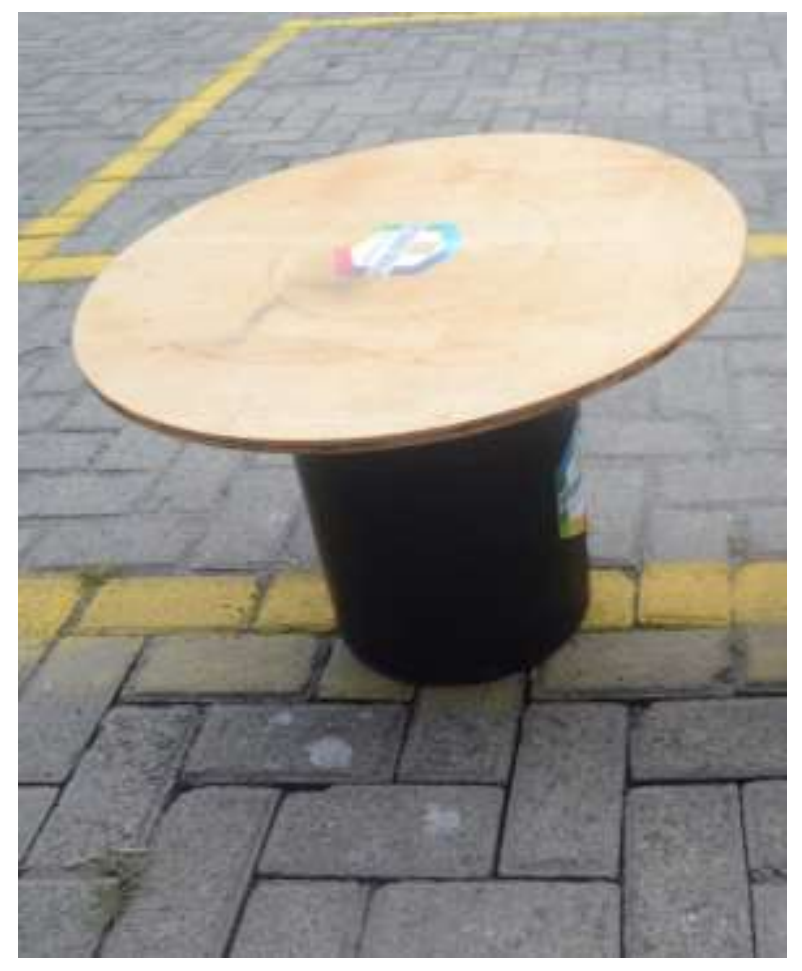

Gambar 6. Desain meja yang sudah jadi 


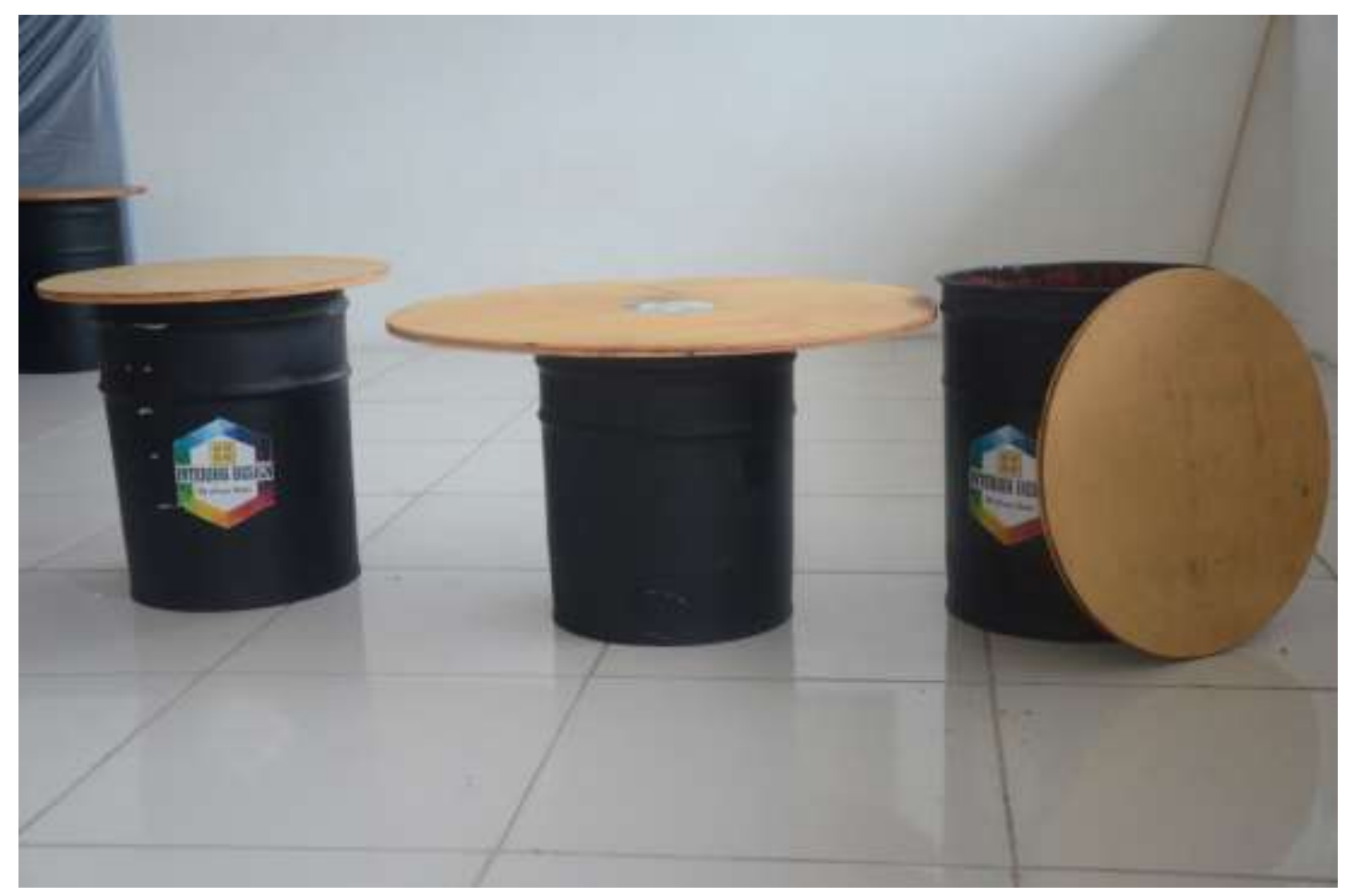

Gambar 7. Meja dan tempat duduk yang sudah dibuat

\section{KESIMPULAN}

Berdasarkan penjelasan dan penelitian yang dilakukan dalam membuat karya desain interior ini dengan menggunakan tong bekas dan triplek maka ada beberapa kesimpulan yang didapat adalah :

1. Dengan menggunakan bahan bekas berupa tong dan triplek dapat juga membuat sebuah furniture atau sebuah karya untuk desain interior yang minimalis dan ekonomis.

2. Karya yang dibuat masih terlihat sangat sederhana tanpa adanya desain yang lain agar membuat tampilan meja dan kursi terlihat lebih menarik dan sempurna.

3. Bahan yang digunakan adalah bahan dari bekas industri.

\section{V.SARAN}

Saran untuk kedepannya adalah :

1. Ditambahkan nya sebuah gambar yang dapat diletakkan pada meja atau kursin untuk menambah kesan indah terhadap karya tersebut.

2. Dapat menambahkan alat untuk penyangga kursi agar terlihat kesan menarik.

\section{DAFTAR PUSTAKA}

[1] Rizky,Oktrivani,Putri, "PEMANFAATAN LIMBAH BIJI SALAK MENJADI MANIK UNTUK PRODUK FASHION”, e-Proceeding of Art \& Design, Vol. 2, No. 3 Desember 2015 
[2] Rustan, Surianto. (2009). Layout dan Dasar Penerapannya. Jakarta: PT Gramedia Pustaka Utama.

[3] Fathwa Rizza Hanggara. (2011). PEMANFAATAN BARANG BEKAS SEBAGAI MEDIA BERKARYA TOPENG DALAM PEMBELAJARAN SENI RUPA DI KELAS VII A SMP NEGERI 1 MAYONG JEPARA, Skripsi, Universitas Negeri Malang.

[4] Suwardikun. W, Didit. 2000. Merubah Citra Melalui Perubahan Logo. Bandung: ITB Library.

[5] Suwardikun, W. Didit. 2002. Perubahan Logo Perusahaan, Sebuah Analisis Visual (Studi Kasus: PT. Astra Internasional, Garuda Indonesia, Unocal 76). Tesis, Fakultas Seni Rupa dan Desain, Desain Komunikasi Visual, Institut Teknologi Bandung, Bandung.

[6] Sachari, A., \& Sunarya, Y. Y. (2002). Sejarah dan Perkembangan Desain dan dunia kesenirupaan di Indonesia. Penerbit ITB.

[7] Alexander, C, (1963). Notes on the Synthesis of Form. Cambridge. MA: Harvard University Press

[8] Archer,L. B., (1965). Systematic Method for Designers. London: The Design Council.

[9] Sularko, Herdi., Victor N. Prawata., \& Michel widranata. 2008. How Do They Think: Rekaman Proses Pembuatan Aset Perusahaan Paling Berharga. Jakarta : Mosher Publishing.

[10]Carter, David. E. 2005. Logo Redesigned: How 200 Companies Successfully Changed Their Image. New York: Harper Collins.

[11] https://www.dekoruma.com/artikel/15593/desain-interior-dekoruma, didownload pada tanggal 27 Januari 2019 